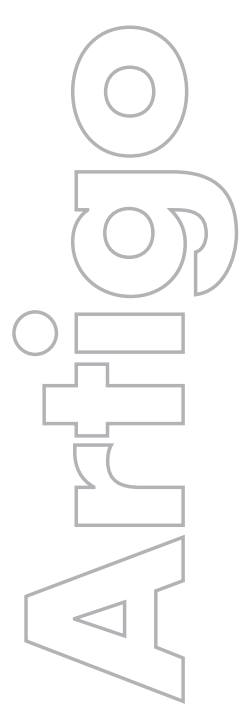

revista

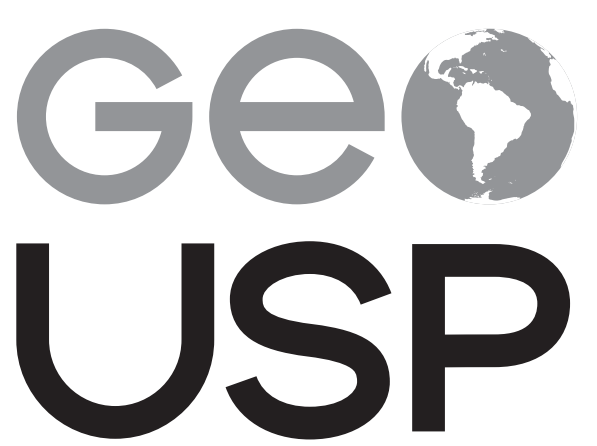

espaço e tempo

Volume $22 \cdot n^{\circ} 1$ (2018)
Epistemologia da Geografia e espaço geográfico: a contribuição teórica de Milton Santos

\section{Leandro Vieira Cavalcante \\ UECE \\ Luiz Cruz Lima \\ UECE}

p. $061-075$

Como citar este artigo:

CAVALCANTE, L. V.; LIMA, L. C. Epistemologia da Geografia e espaço geográfico: a contribuição teórica de Milton Santos. Geousp - Espaço e Tempo (Online), v. 22, n. 1, p. 061-075 mês. 2018. ISSN 2179-0892.

Disponível em: <http://www.revistas.usp.br/geousp/article/ view/127769 >. doi: http://dx.doi.org/10.11606/issn.2179-0892. geousp.2018.127769.

\section{(c) $\underset{\mathrm{BY}-\mathrm{NC}}{\mathrm{NC}}$}

Este artigo está licenciado sob a Creative Commons Attribution 4.0 License. 


\title{
Epistemologia da Geografia e espaço geográfico: a contribuição teórica de Milton Santos
}

\section{Resumo}

O principal objetivo deste artigo é estabelecer uma relação entre a epistemologia da ciência geográfica e o espaço. Para tanto, parte da contribuição teórica de Milton Santos, que não mediu esforços para avançar no entendimento do objeto da ciência geográfica, revolucionando suas bases epistemológicas. Procuramos sistematizar algumas de suas principais ideias e apresentá-las de forma encadeada, visando facilitar sua compreensão e elucidar alguns questionamentos sobre a epistemologia da geografia. Primeiramente, discutimos a epistemologia da ciência geográfica e seu processo de renovação, evidenciado a partir dos anos 1970, procurando perceber como se insere aí a questão do espaço. Em seguida, tratamos da importância de Milton Santos para a (re)definição do objeto geográfico e discorremos sobre a natureza do espaço geográfico de acordo com as definições do autor.

Palavras-chave: Epistemologia da geografia. Espaço geográfico. Milton Santos.

\section{Epistemology of Geography and geographical space: the theoretical contribution of Milton Santos}

\begin{abstract}
Establishing a relationship between the epistemology of geographical science and space is the main purpose of this article. To do so, we start from the theoretical contribution of Milton Santos, who made great efforts to advance understanding of the objective of geographical science, revolutionizing its epistemological bases. We attempt to systematize some of the author's main ideas, and to present them in a concatenated way to facilitate the comprehension of these ideas and to elucidate some of the questions surrounding the epistemology of geography. First, we discuss about the epistemology of geographical science and the process of its renovation, evidenced from the 1970s, trying to perceive how the matter of space is
\end{abstract}


inserted. Next, we address the importance of Milton Santos to the re-definition of the geographical object. Then, we discuss the nature of the geographical space according to the definitions presented by that author.

Keywords: Epistemology of Geography. Geographical space. Milton Santos.

\section{Introdução}

Objetivo principal deste artigo é estabelecer uma relação entre a epistemologia da Geografia e o seu objeto de estudo, o espaço geográfico. Parte-se sobretudo da leitura do geógrafo Milton Santos, que produziu importantes obras ao longo de sua vida e que deu grandes contribuições no sentido de avançar no entendimento do objeto da ciência geográfica, revolucionando suas bases epistemológicas. Muito já foi debatido acerca da importância de Milton Santos para a renovação da Geografia brasileira (e latino-americana) e para a compreensão da natureza do espaço geográfico, todavia ainda cabe investigar suas contribuições para o desenvolvimento epistemológico da própria Geografia - é isso que pretendemos fazer, brevemente, no decorrer deste artigo.

De um modo geral, a compreensão da epistemologia da Geografia parte, primeiramente e acima de tudo, do entendimento de seu objeto de estudo. Isso porque o que justamente confere um teor científico a uma dada ciência é a existência de um objeto que lhe seja particular. A partir da leitura de Milton Santos, fica muito clara essa preocupação do autor em delimitar precisamente o objeto da ciência geográfica, negligenciado por toda uma geração de geógrafos que não tinham o espaço no cerne de suas preocupações. $\bigcirc$ autor demonstra sua preocupação com essa negligência, muitas vezes proposital, ao afirmar que "desgraçadamente, porém, de todas as disciplinas sociais, a geografia foi a que mais se atrasou na definição do seu objeto e passou, mesmo, a negligenciar completamente esse problema" (Santos, 2008, p. 144).

Milton Santos, especialmente em Por uma Geografia nova, discute a importância da definição do objeto da Geografia para o próprio desenvolvimento dessa ciência, tendo em vista que muito já se sabia sobre a Geografia em si, mas quase nada sobre o seu objeto de estudo. Isso decorria, segundo o autor, do grave erro teórico e metodológico de confundir a ciência com o seu objeto ao se pensar que discutir Geografia era o mesmo que discutir o espaço. "Se uma ciência se define por seu objeto, nem sempre a definição da disciplina leva em conta esse objeto. Este é, particularmente, o caso da geografia, cuja preocupação com seu objeto explícito - o espaço social - foi sempre deixada em segundo plano" (Santos, 2008, p. 145).

Nesse sentido, só é possível avançar na construção da epistemologia da Geografia quando houver uma clara definição de seu objeto de estudo, que ainda hoje não é uma unanimidade entre os geógrafos. E foi nessa difícil tarefa que se concentrou Milton Santos ao longo de toda sua trajetória como teórico da ciência geográfica. Uma de suas maiores preocupações era "pensar o espaço", e foi dessa reflexão que emergiram algumas de suas mais importantes contribuições, que inclusive ultrapassaram, e muito, os domínios da Geografia e se estenderam 
para todo o conjunto das ciências humanas e sociais. "Sua colaboração para a construção epistemológica da ciência geográfica é nítida. Pensar o espaço, o território, o território usado era o objeto de seu trabalho" (Elias, 2003, p. 133).

Entre todas as obras publicadas por Milton Santos, em diferentes idiomas e acerca de diversos temas, escolhemos nos apoiar especialmente naquelas em que a questão do espaço assume um lugar central. São elas: Por uma Geografia nova (1978), Espaço e método (1985), Metamorfoses do espaço habitado (1988), Técnica, espaço e tempo (1994) e A natureza do espaço (1996). 'Ainda hoje, essas obras são algumas das principais referências quando se trata do espaço geográfico, em especial a última, que reúne um consistente conjunto teórico desenvolvido pelo autor e onde é apresentada uma relevante construção epistemológica acerca do espaço. A leitura de todas essas obras, com destaque para Por uma Geografia nova e A natureza do espaço, nos permitiu avançar na proposta aqui apresentada.

Adverte-se, todavia, que não é nosso objetivo, aqui, esgotar todas as possibilidades de apreensão da teoria miltoniana da Geografia e do Espaço. Nem mesmo promover um debate denso acerca da contribuição epistemológica de Milton Santos para a ciência geográfica. Nosso propósito central é sistematizar algumas das principais ideias defendidas pelo autor e apresentá-las de forma encadeada, visando facilitar a compreensão dessas ideias e elucidar alguns questionamentos acerca da epistemologia da Geografia e da construção do conceito de espaço. Primeiramente discutimos, de forma breve, acerca da epistemologia da ciência geográfica e de seu processo de renovação evidenciado a partir dos anos 1970, intentando perceber como se insere a questão do espaço. Em seguida, tratamos da importância de Milton Santos para a (re)definição do objeto geográfico. Posteriormente discorremos a respeito da natureza do espaço e sobre os principais pares indissociáveis tomados por Milton Santos para conceituá-lo.

\section{Epistemologia e a renovação da ciência geográfica}

$\bigcirc$ debate acerca da epistemologia da Geografia remete, na maioria das vezes, à compreensão de seu desenvolvimento histórico, à análise das obras de seus principais autores clássicos, ao conhecimento de seus paradigmas mais importantes e à discussão de seus conceitos e construções teóricas. Apenas a partir do entendimento da epistemologia da Geografia é que é possível contribuir para o desenvolvimento dessa ciência, ainda muito carente de um debate relativo à sua episteme, como afirma Moreira (2006, 2007, 2012). Para o autor, a construção de uma epistemologia crítica da Geografia passa pela análise de suas matrizes teóricas, forjadas pela estrutura Natureza-Homem-Economia (Moreira, 2006), pelo resgate de sua práxis, dada pela valorização da presença do espaço na teoria e na prática geográficas (Moreira, 2012), e pelo debate de sua ontologia (Moreira, 2007), seja do espaço seja da própria Geografia. Discutir a epistemologia da Geografia é, antes de mais nada, refletir sobre a sua teoria, sobre a filosofia do conhecimento por ela gerado.

O conhecimento geográfico vem sendo produzido de forma dinâmica e intensa, marcado pela existência de diferentes paradigmas, os quais contribuem sobremaneira para o desenvolvimento da ciência geográfica e para a renovação de seu objeto. De acordo com Sposito

1 Além dessas, a questão do espaço também foi o objeto central de discussão em obras como Espaço e sociedade (1979), O espaço dividido (1979), Pensando o espaço do homem (1982) e O espaço do cidadão (1987), entre outras. 
(2001), esses paradigmas são fundamentais na orientação teórica e metodológica da produção do conhecimento geográfico, já que eles expressam um conjunto de ideias, teorias e doutrinas que, constituídas por intermediação do método, orientam o savoir-faire dos geógrafos. Para Moreira (2006, p. 13), três são as fases que a Geografia conhece desde sua sistematização por Karl Ritter e Alexander von Humboldt, no século XIX, diferenciadas por seus respectivos paradigmas: paradigma holista da baixa modernidade; paradigma fragmentário da modernidade industrial; paradigma holista da hipermodernidade.

No interior desses paradigmas, que expressam distintas fases da ciência geográfica, bem como da produção de seu conhecimento, o objeto da Geografia era visto de acordo com as ideias predominantes de cada período e a partir da influência dos principais pensadores de cada época. Conforme demonstram autores como Moraes (1983), Andrade (2006), Moreira (2006) e Claval (2013), já se defendeu, por exemplo, que a superfície terrestre era o principal objeto da ciência geográfica. Em seguida falou-se da paisagem, do meio, da região, da diferenciação de áreas, da relação homem-meio, da natureza, entre outros objetos, até chegar ao espaço tomado atualmente como verdadeiro objeto da Geografia. Todavia, para autores como Lévy e Lussault (2013) e Claval (2013), entre outros, o objeto da Geografia não seria propriamente o espaço, e sim a "dimensão espacial da sociedade". E esse reconhecimento do espaço como o objeto da Geografia é algo relativamente recente, emergindo com mais intensidade no cenário geográfico mundial sobretudo no final da década de 1970 e durante toda a década de 1980.

A chamada "crise dos paradigmas", período evidenciado no decorrer das décadas de 1970-80, coincide com o movimento de renovação da Geografia e com a redefinição de seu objeto de estudo, processos nos quais Milton Santos teve uma participação efetiva, notadamente a partir da publicação de Por uma Geografia nova, em 1978. Além dessa obra, Moreira (2007) destaca também as contribuições de Massimo Quaini, em Marxismo e Geografia (1979), e de Yves Lacoste, na já clássica A Geografia serve, antes de mais nada, para fazer a guerra (1976). $O$ conjunto dessas três obras, além de outras, contribuiu significativamente para pôr em xeque os paradigmas então predominantes na Geografia e para lançar as bases de uma teoria geográfica verdadeiramente preocupada com as questões sociais, até então bastante negligenciadas. Para Moreira (2007), nessas obras reuniu-se o essencial das questões e ideias que levaram à renovação que se veria na sequência, ultrapassando o domínio da Geografia Científica e atingindo em cheio a Geografia Escolar, modificando por completo a episteme dessa ciência, como também dessa disciplina.

Esse processo de renovação da Geografia, a partir de uma crítica ferrenha especialmente ao paradigma teorético-quantitativo² (ou paradigma fragmentário da modernidade industrial), colaborou decisivamente para mudar a forma de se fazer Geografia ao redor do mundo, quando os estudos geográficos passaram a denotar uma atenção especial às relações sociais e às contradições inerentes ao modo de produção capitalista, por exemplo. Para isso, houve uma grande renovação também das teorias e dos métodos utilizados pela Geografia, preocupada em fugir do viés neopositivista predominante nessa ciência até o final do século XX. Além disso, a partir desse movimento de renovação há um importante debate em torno do objeto

2 Centrado na abordagem quantitativa dos processos geográficos e ancorado nos usos de métodos matemáticos e de modelos de representação e análise do espaço, além de marcado pela neutralidade científica. 
da ciência geográfica, passando o espaço a ser o centro das preocupações dos geógrafos (pelo menos de uma parte deles). Com isso, a Geografia não foi apenas renovada, como também redescoberta, a partir de uma valorização do espaço como seu objeto de estudo, segundo afirmam Moraes e Costa (1984), em Geografia crítica: a valorização do espaço.

Como argumenta Moreira (2007, p. 36), "a renovação deu-se essencialmente com o conceito de espaço, num alcance limitado. Todavia, mexeu ela com os pilares de um saber anos a fio refratário a grandes mudanças. E sem dúvida preparou terreno para mudanças subsequentes". Nesse sentido e de acordo com Claval (2013), entre 1980 e 1990 (se estendendo até o presente), há uma importante valorização do espaço na teoria social; com isso, a Geografia reivindica um novo status, focada na dimensão espacial da sociedade. Para Moreira (2007, p. 15), o final do século XX consagra a Geografia como a ciência do espaço e o geógrafo como o especialista de sua organização. Assim, a partir dessa renovação da Geografia e da valorização do espaço, a epistemologia dessa ciência conhece um novo impulso.

A esse respeito, Moreira (2012, p. 17) apresenta cinco eixos de reflexão que indicam essa onda de renovação crítica do pensamento geográfico, bem como de sua epistemologia, a partir do entendimento do espaço como objeto de investigação: o espaço como condição de reprodução das relações sociais de produção (Lefebvre, 1974); o espaço como mediação das relações de dominação de classes e de poder (Lacoste, 1976); o espaço como estrutura de valorização do capital (Harvey, 1977); o espaço como formação social (Santos, 1978); a sociedade como natureza socializada e história naturalizada (Quaini, 1979). Todos esses modos de ver e apreender o espaço, a partir de bases marxistas, vêm colaborando para o progresso observado na Geografia no decorrer das últimas quatro décadas, e é a contribuição fornecida por Milton Santos que destacamos nos tópicos seguintes.

\section{Milton Santos e a (re)definição do objeto geográfico}

Milton Santos, entre outros importantes geógrafos, ${ }^{3}$ contribuiu para modificar a forma como concebemos e trabalhamos o espaço, e com isso forneceu elementos indispensáveis para a renovação da ciência geográfica, como já destacamos. Para ele, o espaço estaria no cerne do entendimento da formação social, tomada como teoria e método necessários para a compreensão geográfica dos fenômenos (Santos, 1977), sendo o próprio espaço uma formação social. De acordo com Santos (1977), a base para a elucidação da formação econômica e social é a produção, isto é, o trabalho humano voltado para transformar o espaço. Ainda conforme o autor, não há como falar de formação econômica e social sem incluir a categoria espaço; trata-se, portanto, de uma formação econômica, social e também espacial. Aqui o espaço adquire um papel fundamental na compreensão das atividades econômicas e sociais, uma vez que absolutamente nada se dá fora dele e sem que nele causem as mais distintas implicações, sem que haja uma transformação nesse/desse espaço.

Ainda consoante Santos (1977, p. 28), modo de produção, formação social e produção

3 No contexto nacional destacam-se, além de Milton Santos: Ruy Moreira, Antônio Carlos Robert Moraes, Armando Corrêa da Silva, Manuel Correia de Andrade, Ana Fani Alessandri Carlos, Ariovaldo Umbelino de Oliveira, Armen Mamigoniam, José Willian Vesentini, Rosa Ester Rossini, Paulo César da Costa Gomes, Arlete Moysés Rodrigues, Maurício de Almeida Abreu, Léa Goldenstein, Wanderley Messias da Costa, Amélia Luisa Damiani, Carlos Walter Porto Gonçalves e Roberto Lobato Corrêa, entre outros. 
do espaço são categorias e processos interdependentes, apesar de estarem profundamente interligados, tendo afirmado que "todos os processos que formam um modo de produção são histórica e espacialmente determinados num movimento de conjunto, e isto através de uma formação social". Ou seja, mais uma vez, não há formação econômica e social sem que ela seja também formação espacial. Trata-se, na verdade, de uma formação socioespacial. Nessa perspectiva, modo de produção, formação social e espaço são noções que devem ser apreendidas em conjunto, haja vista que não podemos compreendê-las separadamente. É tanto que, por exemplo, o espaço é um testemunho dos modos de produção e ao mesmo tempo assume um papel ativo na sua reprodução, conforme indica o autor em várias de suas obras. Esse foi o pontapé inicial para a proposição de uma teoria crítica do espaço por Milton Santos, culminando na publicação de Por uma Geografia nova, redefinindo o que até então se entendia por "espaço" e introduzindo uma abordagem marxista na compreensão do papel do espaço na formação social, influenciando toda uma geração de geógrafos, notadamente os brasileiros.

Em Por uma Geografia nova são apresentadas as bases para a renovação da ciência geográfica, a partir da clara definição do que deveria ser seu objeto de estudo, como já foi ressaltado. Nessa obra, Milton Santos fornece elementos que nos ajudariam a analisar criticamente o percurso histórico da Geografia, principalmente da Geografia Clássica e da New Geography, que faziam uma análise a-espacial dos fenômenos sociais e estavam repletas de ideologias embutidas em suas teorias e métodos. Além disso, o autor propôs a criação de uma Geografia Nova, renovada, que evidenciasse o papel do espaço e que refletisse acerca da participação da sociedade na sua produção. Milton Santos, nessa obra, lança assim as bases para se pensar na construção de uma Geografia verdadeiramente crítica, diferente das muitas geografias que vinham sendo feitas, que estavam a serviço dos interesses burgueses que financiavam e ditavam a produção do conhecimento geográfico, comprometidas ora em fazer a guerra (Lacoste, 1976), ora em reproduzir o capital (Harvey, 2006).

Para Elias (2003, p. 136), a partir da publicação de Por uma Geografia nova, Milton Santos mergulha na epistemologia da Geografia e na dialética, marcando um tempo de mudança para a ciência geográfica, um período de renovação, de busca de novos paradigmas. Já para Moreira (2007, p. 28), a visão estruturalista do espaço como instância trazida à Geografia por Milton Santos ofereceu o elemento essencial à crítica da abordagem neopositivista. Com isso, ainda de acordo com Moreira (2007), ocorrem uma assimilação e uma identidade recíproca que fazem dessa obra a principal referência da renovação, o discurso sistematizado que ela procurava. Milton Santos forneceu o conteúdo crítico do qual o movimento de renovação da Geografia brasileira necessitava ao final dos anos 1970, cumprindo um papel essencial para o que se viu nos anos seguintes, através da tentativa de construção de uma Geografia nova.

Uma das principais contribuições advindas com a publicação de Por uma Geografia nova, reforçada nas obras que a sucederam, foi a importância dada ao espaço, defendido por Milton Santos como o elo de indissociabilidade da natureza com a sociedade, e que por essa razão ele - o espaço - deveria ser considerado como o objeto da ciência geográfica. Nessa obra, o espaço assume um lugar central, visto que somente a partir do seu entendimento foi possível aprofundar a discussão concernente a uma outra epistemologia para a Geografia. Para Santos (2008, p. 21), "o estudo da produção do espaço deve funcionar como uma verdadeira teoria do 
espaço humano", como o meio pelo qual a realidade pode ser também apreendida e analisada. Foi nesse sentido que Milton Santos desenvolveu sua argumentação ao longo de toda a obra, ciente de sua contribuição e das resistências que enfrentaria (e que de fato enfrentou).

$\bigcirc$ tom da crítica feita por Milton Santos fica mais evidente especialmente quando ele passa a se referir à Geografia como a "viúva do espaço". Isso se deu sobretudo porque "sua base de ensino e de pesquisa [sempre foi] a história dos historiadores, a natureza 'natural' e a economia neoclássica, todas as três tendo substituído o espaço real, o das sociedades em seu devir, por qualquer coisa de estático ou simplesmente de não existente, de ideológico" (Santos, 2008, p. 118). Segundo o autor, era por isso que tantos geógrafos discutiam cada vez mais sobre a Geografia - uma palavra vazia de conteúdo - e quase nunca sobre o espaço como o objeto dessa ciência. Em virtude disso, "a definição deste objeto, o espaço, tornou-se difícil e a da geografia, impossível" (Santos, 2008, p. 119).

Esse quadro só passou a ser alterado quando se definiu precisamente o objeto da ciência geográfica, por meio da influência conjunta de Milton Santos e de uma série de outros ilustres geógrafos, dispersos ao redor de todo o mundo. No caso da Geografia brasileira, a preponderância de Milton Santos foi ímpar, tendo assumido o principal lugar de destaque no movimento de renovação dessa ciência e na redefinição de seu objeto de estudo, consoante se pode notar a partir da leitura de Santos (1982), Carlos (1996), Souza (1996), Lévy (2007), Silva (2009), Grimm (2011), Melgaço e Prouse (2017), entre outros. Nas suas palavras, repletas de otimismo, é possível observar a crença em um outro futuro possível para a Geografia: "É chegado o tempo em que uma nova geografia pode ser criada, porque o homem começa, um pouco em toda parte, a reconhecer no espaço trabalhado por ele uma causa de tantos dos males que o afligem no mundo atual" (Santos, 2008, p. 262).

\section{A natureza do espaço geográfico de acordo com Milton Santos}

As contribuições de Milton Santos para o entendimento do espaço são apresentadas especialmente nas obras Por uma Geografia nova, Espaço e método, Metamorfoses do espaço habitado, Técnica, espaço e tempo e A natureza do espaço, como já destacamos. Em cada uma dessas obras encontramos uma consistente teoria geográfica do espaço, apreendido a partir de um conjunto de conceitos e categorias que auxiliam na sua objetivação. Milton Santos foi um verdadeiro teórico do espaço, ou filósofo do espaço, como se referem alguns autores, e dedicou grande parte de seu esforço pessoal e intelectual na busca por um aprofundamento da definição do objeto da ciência geográfica. Sem dúvida, o espaço foi o tema central de sua teoria, de sua Geografia e, portanto, de sua "trajetória epistemológica", como indica Grimm (2011).

Não cabe aqui apresentar um retrospecto da definição de espaço segundo Milton Santos, já que tal empreitada despenderia uma grande quantidade de páginas; ${ }^{4}$ como também não será apresentada uma análise de como o espaço foi abordado em cada uma das obras citadas anteriormente. Todavia, cabe indicar, mesmo que brevemente, como Milton Santos pensava o espaço, como ele o conceituava e adjetivava. Essa atividade é especialmente difícil porque não há apenas uma única e simples definição de espaço em Milton Santos. Esse foi um conceito

4 Assim como fez Moraes (2013) ao analisar de que forma Milton Santos concebeu e utilizou o conceito de território em suas obras. 
aprofundado pelo autor no decorrer de sua trajetória intelectual - não se trata, portanto, de um conceito acabado e fechado nele mesmo, uma vez que ele comporta várias interpretações possíveis. De um modo geral, pode-se afirmar que há várias definições de espaço nas obras de Milton Santos, que na maioria das vezes se complementam entre si, já que o espaço é uno e indivisível, como o próprio autor o entende.

Milton Santos sempre esteve ciente dessa dificuldade de definição do espaço: "Não sejamos injustos. Compreende-se porque os geógrafos se dedicaram muito mais à definição de geografia do que à definição de espaço. Esta última é uma tarefa extremamente árdua" (Santos, 2008, p. 150). E essa dificuldade reside especialmente em virtude do entendimento do espaço como um processo histórico, em constante modificação, produto de uma sociedade que não é, nem de longe, estática. Nessa perspectiva, Santos (2008, p. 151) chegou a afirmar: "Mas o que é esse espaço geográfico? Sua definição é árdua, porque a sua tendência é mudar como processo histórico, uma vez que o espaço geográfico é também o espaço social". E ao conceber o espaço como uma categoria histórica, o autor avança em considerar também a dimensão temporal na sua configuração, bem como corrobora com a apreensão do espaço como algo inerente às relações sociais. Foi, sem sombra de dúvidas, uma contribuição importante, que permitiu tomar o espaço como "instância da sociedade" 5 .

De acordo com Santos (1985), o espaço não seria formado apenas pelos objetos geográficos, naturais e/ou artificiais; o espaço é tudo isso mais a sociedade. $\bigcirc$ autor acrescenta também que para analisar o espaço é necessário apreender sua relação com a sociedade, pois é ela quem dita a compreensão dos efeitos dos processos que se dão desde a produção ao uso e à organização do espaço. Ainda segundo Santos (1985, 2008), esse espaço não tem nenhuma capacidade explicativa por si só, sendo, portanto, indispensável considerar a dimensão social que the dá vida. Assim, "o espaço impõe sua própria realidade; por isso a sociedade não pode operar fora dele. Consequentemente, para estudar o espaço, cumpre apreender sua relação com a sociedade" (Santos, 1985, p. 49). Espaço e sociedade são, portanto, indissociáveis, formando um quadro único no qual a história se dá.

O espaço que interessa a Milton Santos - e, por sua vez, à Geografia - é o espaço social, já que a essência do espaço é social (Santos, 2008), uma vez que ele é constantemente (re)produzido pelas relações sociais. Para Lefebvre (1974), sociólogo que teve uma expressiva influência sobre o pensamento miltoniano, cada sociedade produz um espaço que lhe é particular, o seu próprio espaço, e dessa forma, ainda segundo o referido autor, o espaço (social) seria então um produto (social). Esse espaço social é indispensável para a realização das atividades humanas, sejam elas sociais, culturais, políticas e/ou econômicas, já que ele é o lugar de morada do homem, de vida, de produção e de trabalho. Sendo assim, "o espaço se define como um conjunto de formas representativas de relações sociais do passado e do presente e por uma estrutura representada por relações sociais que estão acontecendo diante dos nossos olhos e que se manifestam através de processos e funções" (Santos, 2008, p. 153).

5 Entender o espaço como uma "instância social" é considerar o seu papel ativo na estrutura social, assim como as instâncias econômicas, políticas e culturais-ideológicas, haja vista que a essência do espaço é social, segundo afirma Santos (2008, p. 177). 
Esse entendimento do espaço como testemunho da história é outra grande contribuição enaltecida por Milton Santos. Para ele, o "espaço deve ser considerado como um conjunto de relações realizadas através de funções e de formas que se apresentam como testemunho de uma história escrita por processos do passado e do presente" (Santos, 2008, p. 153). Nesse sentido, o espaço nunca pode ser explicado apenas pelo presente, já que ele é sempre um processo de construção histórica, uma herança dos modos de produção do passado. Santos (2008, p. 181-182) reafirma esse posicionamento ao dizer que "de fato, o espaço não pode ser apenas um reflexo do modo de produção atual porque é a memória dos modos de produção do passado. Ele sobrevive, pelas suas formas, à passagem dos modos de produção ou de seus momentos".

Em nossa opinião, Milton Santos também avançou ao considerar o espaço como o produto da relação sociedade-natureza, constituída por meio do trabalho humano e por intermédio das técnicas. $\bigcirc$ autor considera que o espaço, independentemente do seu período histórico, é sempre um resultado da produção, ou seja, da transformação da natureza e da reprodução das relações sociais. Para ele, "a produção, pois, supõe uma intermediação entre o homem e a natureza, através das técnicas e dos instrumentos de trabalho inventados para o exercício desse intermédio" (Santos, 2008, p. 202). Nessa produção estariam embutidas a vida em sociedade e a divisão do trabalho, fundamentais para o processo de produção do espaço. Em resumo, Milton Santos reafirma o caráter histórico e dinâmico do espaço e enaltece o papel da sociedade, por meio do trabalho, na sua constante reprodução, através do próprio movimento dialético que une espaço e sociedade.

Outra contribuição dada por Milton Santos para a epistemologia da Geografia é apresentada sobretudo na obra $A$ Natureza do Espaço, na qual o autor vai expor, de forma sistematizada, toda sua proposição teórica desenvolvida acerca do espaço ${ }^{6}$. Nessa obra, dois pontos principais merecem destaque: um é a valorização dada à técnica, entendida como um elemento fundamental para a compreensão do espaço (e do tempo), e o outro é o debate em torno da conceituação do espaço como sistema de objetos e ações. E isso foi construído levando-se em conta a força do lugar em meio à globalização e à emergência de um novo período histórico-geográfico, chamado por Santos $(1996,2009)$ de técnico-científico-informacional, responsável por alterar significativamente a forma e o conteúdo espaciais.

De acordo com Grimm (2011), ao considerar o fenômeno técnico na produção e na apreensão do espaço, Milton Santos contribuiu para a construção de uma teoria social crítica do espaço geográfico, trazendo grandes rebatimentos no interior da Geografia e das ciências sociais de uma maneira geral, ao apresentar uma nova proposta de teorização tanto para o espaço quanto para as ciências encarregadas do seu estudo. "Na proposta teórica de Milton Santos, ressalta-se a necessidade de reconhecer o papel que o fenômeno técnico apresenta nas transformações ocorridas no espaço geográfico" (Grimm, 2011, p. 119). A esse respeito, Santos (2009, p. 49) vai afirmar que o enfoque dado à técnica é fundamental quando se trata de en-

6 Segundo Elias (2003), com A natureza do espaço, Milton Santos reforça sua epistemologia do espaço, contribuindo para a construção de uma teoria social. 
carar a escorregadia relação entre o tempo e o espaço na Geografia, e sua apreensão conjunta se trata verdadeiramente de uma preocupação epistemológica totalizadora, vindo a técnica a ser o traço da união, histórica e epistemológica, entre espaço e tempo ${ }^{7}$.

E isso vai se refletir na própria configuração do espaço, tanto em sua forma quanto em seu conteúdo, demonstrando a maneira como se comportam os sistemas de objetos e de ações que configuram e dinamizam o espaço. Não por menos, Santos (2009, p. 109) vai considerar que "o espaço é a síntese, sempre provisória, entre o conteúdo social e as formas espaciais", estando "formado por um conjunto indissociável, solidário e também contraditório, de sistemas de objetos e sistemas de ações, não considerados isoladamente, mas como o quadro único no qual a história se dá" (p. 63). De acordo com o autor, esses sistemas de objetos e sistemas de ações interagem: de um lado, "os sistemas de objetos condicionam a forma como se dão as ações e, de outro lado, o sistema de ações leva à criação de objetos novos ou se realiza sobre objetos preexistentes. É assim que o espaço encontra sua dinâmica e se transforma" (Santos, 2009, p. 63). Esse entendimento nos ajuda a perceber o papel da compreensão do espaço na redefinição da própria ciência geográfica.

Ao considerar o espaço um conjunto de sistemas de objetos e de sistemas de ações, Milton Santos contribuiu, em nosso entendimento, para aproximar os debates realizados no que se chama de Geografia Física e Geografia Humana. Isso porque é no espaço onde se encontram esses dois campos da ciência geográfica, ou seja, é o espaço o elemento-chave que une Geografia Física e Geografia Humana, que garante o caráter unitário a essa ciência - já que os geógrafos, todos eles, se dedicam ao estudo do espaço, embora utilizando diferentes teorias e métodos para a sua apreensão. É a compreensão que temos do espaço que garante a geograficidade de nossos estudos, conforme afirma Santos (2009, p. 77): "a partir do entendimento que tivermos do que deve ser o objeto da disciplina geográfica, [é que] ficamos em condições de tratar, geograficamente, os objetos encontrados".

Para o autor, o que interessa aos geógrafos são os objetos, naturais e/ou artificiais, como uma montanha, uma cidade, um rio, um porto, uma lavoura, um estuário etc. "Para os geógrafos, os objetos são tudo o que existe na superfície da Terra, toda herança da história natural e todo resultado da ação humana que se objetivou" (Santos, 2009, p. 72). Uma vez que tudo pode ser considerado objeto, caberia aos geógrafos fazer a sua ligação com as ações, garantindo a indissociabilidade entre objeto e ação e resguardando seus estudos de geograficidade. São as ações que vão garantir o conteúdo social a essas formas espaciais representadas pelos objetos, indicando o papel das intencionalidades na configuração espacial e reafirmando o caráter social no processo de produção do espaço.

Tal visão representa, acima de tudo, o destaque dado à indissociabilidade existente entre materialidade e intencionalidade na configuração do espaço, levando-nos a repensar a ciência geográfica como um todo, pondo em xeque o paradigma sempre atual que representa a dualidade dominante na produção do conhecimento científico na Geografia, responsável por causar ainda hoje uma grande celeuma entre os geógrafos. Além disso, percebe-se que essa concep-

7 Todavia, esse enfoque dado à técnica ainda hoje é passível de inúmeras críticas. Para uma contundente crítica à expressiva valorização dada por Milton Santos à técnica na produção e no entendimento do espaço, ver sobretudo o artigo de Lima (2014). 
ção, centrada nos sistemas de objetos e sistemas de ações, foi construída a partir da utilização de um dos muitos pares indissociáveis empregados por Milton Santos na tentativa de definição do espaço, contribuindo para dotar esse conceito de dinamicidade e vivacidade.

\section{O espaço geográfico: um híbrido (acerca dos pares indissociáveis)}

A utilização de pares conceituais indissociáveis ${ }^{8}$ é algo recorrente ao longo da obra de Milton Santos, sejam eles utilizados para explicar/conceituar o espaço ou não, refletindo a construção teórica do autor no sentido de demonstrar a indissociabilidade da materialidade com a intencionalidade, das formas espaciais com os conteúdos sociais. Por essa razão, na obra desse autor "enxergamos uma teoria geográfica do espaço, um conjunto coerente que nos permite ultrapassar a forma e compreender a essência, a estrutura e os processos, as formas-conteúdo", como afirma Elias (2003, p. 134). A partir do uso desses pares indissociáveis para a objetivação do espaço, fica fácil entender por que Milton Santos o entendia como um hibrido, ou seja, como algo que sempre transita entre noções que se complementam. Vejamos na sequência alguns desses pares indissociáveis trabalhados pelo autor, com o intuito de perceber como eles podem nos ajudar a melhor apreender o espaço, corroborando para o desenvolvimento da epistemologia geográfica e da ontologia do próprio espaço.

Um dos pares utilizados por Milton Santos para definir o espaço esteve centrado na abordagem dos fixos e fluxos, apresentados sobretudo em Metamorfoses do Espaço Habitado. De acordo com o autor, o espaço é sempre formado, ao mesmo tempo, de fixos e de fluxos. "Nós temos coisas fixas, fluxos que se originam dessas coisas fixas, fluxos que chegam a essas coisas fixas. Tudo isso, junto, é o espaço" (Santos, 1994, p. 77). Para Milton Santos, os fixos nos dão o processo imediato do trabalho, sendo eles próprios os instrumentos de trabalho e as forças produtivas em geral, empregados nas instâncias da produção propriamente dita; por outro lado, os fluxos são o movimento, a circulação, e nos ajudam a compreender a distribuição e o consumo. Fixos e fluxos são indissociáveis, haja vista que um origina o outro e dele depende, possibilitando, entre outras coisas, a continuidade do movimento do espaço. A partir daí, "as categorias clássicas, isto é, a produção propriamente dita, a circulação, a distribuição e o consumo, podem ser estudados através desses dois elementos: fixos e fluxos" (Santos, 1994, p. 77).

Outro par trabalhado por Milton Santos foi o de verticalidades e horizontalidades, abordado especialmente nas obras Técnica, espaço e tempo e A Natureza do Espaço. De um modo geral, e de acordo com o autor, as horizontalidades estariam relacionadas ao processo direto da produção, por intermédio dos fixos, e as verticalidades, por sua vez, relacionadas aos outros processos da produção, por intermediação dos fluxos. "Enquanto as horizontalidades são, sobretudo, [o espaço] da produção propriamente dita e o locus de uma cooperação mais limitada, as verticalidades dão, sobretudo, conta dos outros momentos da produção (circulação, distribuição, consumo), sendo o veículo de uma cooperação mais extensa e implacável” (Santos, 1996, p. 93). Nesse sentido, de acordo com Santos (1996, p. 55), "o espaço geográfico, banal em qualquer escala, agrupa horizontalidades e verticalidades", estando composto, inseparavelmente, desse movimento conjunto, atrelado tanto à produção quanto à sociedade como um todo.

8 São indissociáveis porque não existem um sem o outro. Trata-se de pares intrínsecos e inseparáveis, apesar de diferentes, tal qual o próprio espaço e a sociedade. 
Esse debate remete a um outro, bastante frutífero e muito caro ao pensamento miltoniano, referente às noções de sistemas de objetos e sistemas de ações, apresentadas mormente na obra A Natureza do Espaço. O entendimento do espaço como um conjunto indissociável e contraditório de sistemas de objetos e de sistemas de ações representa o ápice da proposição teórica desenvolvida por Milton Santos e voltada para a apreensão do espaço - foi nessa concepção o mais longe que o autor conseguiu chegar ${ }^{9}$. Essa ideia contribuiu consideravelmente para o avanço na forma pela qual o espaço era concebido na/pela Geografia. De acordo com Grimm (2011, p. 226), percebe-se aí a importância que Milton Santos deu à técnica, tratada como objeto e ação, representando a intermediação entre o homem e o meio, cristalizando-se nos objetos e realizando-se nas ações, resultando, portanto, no próprio espaço.

Esses sistemas de objetos e sistemas de ações são, nada mais nada menos, do que a própria manifestação concreta do espaço geográfico, resultante da interação entre as coisas (naturais e/ou artificiais) e a sociedade que lhes anima. Diante disso, eles expressam as formas e os conteúdos do espaço, qual sejam, as formas espaciais e os conteúdos sociais. Sistemas de objetos e sistemas de ações atuam em conjunto, e a existência de um depende da existência do outro - por isso são considerados indissociáveis. De acordo com Santos (2009, p. 64), "considerar o espaço como esse conjunto indissociável de sistemas de objetos e sistemas de ações, assim como estamos propondo, permite, a um só tempo, trabalhar o resultado conjunto dessa interação, como processo e como resultado". A nosso ver, no âmago desse conceito está a temporalidade, levando à periodização como proposta do método para estudar o espaço. Por tratar, teórica e metodologicamente, das formas de tempos passados, registra como "empirização do tempo", demarcando-as como "rugosidades", como observa Santos (2008, p. 173). Mais uma vez, ao considerar o espaço como processo e ao mesmo tempo resultado, o autor evidencia o caráter dinâmico e mutável que assume o espaço, fugindo de uma apreensão meramente estática da realidade socioespacial.

Além desses pares indissociáveis aqui apresentados (fixo-fluxo, verticalidade-horizontalidade, objetos-ações), Milton Santos também trabalhou com os pares configuração territorial-relações sociais, circuitos espaciais da produção-círculos de cooperação, formas espaciais-conteúdos sociais, tecnosfera-psicosfera, e sistemas de engenharia-sistemas de movimento, para citar somente aqueles voltados para a questão do espaço (Santos, 1985, 1994, 1996, 2008, 2009). São noções que se complementam e permitem avançar na compreensão do objeto da ciência geográfica. Esses pares demonstram, de um modo geral, a indissociabilidade da materialidade com a intencionalidade na configuração do espaço, resultante da própria dialética socioespacial, a partir do que discute Soja (1988, 1993), constituída justamente por essa interação entre materialidade e intencionalidade.

\section{Considerações finais}

Ao centrar seus esforços na elucidação de uma teoria do espaço, Milton Santos se consagrou por sua contribuição dada à Geografia, especialmente para a renovação epistemológica da ciência geográfica - renovação essa que ainda está sendo cotidianamente refeita, já que ela

9 Isso porque, depois da publicação de A natureza do espaço, Milton Santos se volta para os estudos do território e da globalização, não tendo mais se dedicado a fundo à lapidação do conceito de espaço. 
nunca foi (e nunca será) acabada. De acordo com o autor, "em qualquer momento, o ponto de partida é a sociedade humana em processo, isto é, realizando-se. Essa realização se dá sobre uma base material: o espaço e seu uso; o tempo e seu uso; a materialidade e suas diversas formas; as ações e suas diversas feições" (Santos, 2009, p. 54). Por isso que sua proposta epistemológica foi totalizadora, já que foram consideradas inúmeras das dimensões que produzem e dinamizam o espaço, a partir da materialidade dos objetos e das formas e da intencionalidade das ações e dos conteúdos sociais.

Talvez tenha sido esse um dos maiores legados deixados por Milton Santos: a centralidade dos estudos do espaço na ciência geográfica. $\bigcirc$ objetivo principal desse autor foi propor um estudo centrado no espaço que fosse, ao mesmo tempo, uma teoria e uma epistemologia (Santos, 2008, p. 23). E esse objetivo foi, em grande parte, cumprido, haja vista que hoje é possível notar que Milton Santos conseguiu, efetivamente, propor uma (nova) teoria e uma (nova) epistemologia para o espaço, bem como para a Geografia. Por certo, na ciência geográfica hodierna, esse autor demarca uma ruptura do "obstáculo epistemológico" de que nos fala Bachelard (1996). Nas palavras de Milton Santos, fica muito clara essa preocupação com o desenvolvimento conjunto de uma teoria e de uma epistemologia, indispensáveis para o avanço de qualquer que seja a ciência:

Acreditamos que uma teoria que não gera, ao mesmo tempo, a sua própria epistemologia, é inútil porque não é operacional, do mesmo modo que uma epistemologia que não seja baseada numa teoria é maléfica, porque oferece instrumentos de análise que desconhecem ou deformam a realidade (Santos, 2008, p. 24).

Milton Santos deixou um grande legado para o desenvolvimento epistemológico da Geografia e para a apreensão do espaço, o qual não pode ser esquecido ou menosprezado. Todavia, suas ideias ainda carecem de ser ampliadas e, sobretudo, debatidas - e, por que não, também superadas, já que a renovação do conhecimento geográfico é constante e necessária. E esse debate é imprescindível e precisa ser realizado corriqueiramente, já que discutindo o espaço estaremos também discutindo a própria Geografia - sem, é claro, cair no erro de achar que a ciência e seu objeto são a mesma coisa. É apenas assim, a partir do debate, que conseguiremos avançar, tanto na direção da construção de uma Geografia nova quanto na melhor compreensão do que seria o espaço. Somente a partir daí é que uma nova epistemologia poderá ser criada, colaborando para romper com antigos paradigmas que ainda rondam o pensamento geográfico contemporâneo e que limitam os horizontes dessa ciência.

\section{Referências}

ANDRADE, M. C. Geografia, ciência da sociedade. Recife: Ed. UFPE, 2006.

BACHELARD, G. A formação do espírito científico: contribuição para uma psicanálise do conhecimento. Rio de Janeiro: Contraponto, 1996.

CARLOS, A. F. (Org.). Ensaios de Geografia contemporânea - Milton Santos: obra revisitada. São Paulo: Hucitec, 1996. 
CLAVAL, P. Histoire de la Géographie. 4. ed. Paris: PUF, 2013.

ELIAS, D. Milton Santos: a construção da geografia cidadã. Revista Geosul, Florianópolis, v. 18, n. 35, p. 131-148, 2003.

GRIMM, F. Trajetória epistemológica de Milton Santos: uma leitura a partir da centralidade da técnica, dos diálogos com a economia política e da cidadania da práxis. Tese (Doutorado em Geografia Humana) - Faculdade de Filosofia, Letras e Ciências Humanas, Universidade de São Paulo, São Paulo, 2011.

HARVEY, D. A produção capitalista do espaço. São Paulo: Annablume, 2006.

Urbanismo y desigualdad social. Madrid: Siglo Veintiuno, 1977.

LACOSTE, Y. La Géographie, ça sert, d'abord, à faire la guerre. Paris: Maspero, 1976.

LEFEBVRE, H. La production de l'espace. Paris: Anthropos, 1974.

LÉVY, J. (Org.). Milton Santos : philosophe du monde, citoyen do local. Lausanne: Presses Polytechniques, 2007.

LÉVY, J.; LUSSAULT, M. Dictionnaire de la géographie et de l'espace des sociétés. Paris: Belin, 2013.

LIMA, A. M. Geografia: filosofia das técnicas? Reflexões para se pensar uma geografia do trabalho. Revista Pegada, Presidente Prudente, SP, v. 15, n. 2, p. 19-48, 2014.

MELGAÇO, L.; PROUSE, C. (Org.). Milton Santos: a pioneer in critical geography from the Global South. Berlim: Springer, 2017.

MORAES, A. C. R. Território na geografia de Milton Santos. São Paulo: Annablume, 2013.

Geografia: pequena história crítica. 2. ed. São Paulo: Hucitec, 1983.

; COSTA, W. M. Geografia crítica: a valorização do espaço. São Paulo: Hucitec, 1984.

MOREIRA, R. Geografia e práxis: a presença do espaço na teoria e na prática geográficas. São Paulo: Contexto, 2012.

Pensar e Ser em Geografia: ensaios de história, epistemologia e ontologia do espaço geográfico. São Paulo: Contexto, 2007.

Para onde vai o pensamento geográfico? Por uma epistemologia crítica. São Paulo: Contexto, 2006.

QUAINI, M. Marxismo e Geografia. Rio de Janeiro: Paz e Terra, 1979.

SANTOS, M. A natureza do espaço. 4. ed. São Paulo: EdUSP, 2009.

Por uma Geografia nova. 6. ed. São Paulo: EdUSP, 2008.

Técnica, espaço e tempo. 2. ed. São Paulo: Hucitec, 1996.

Metamorfoses do espaço habitado. 3. ed. São Paulo: Hucitec, 1994. 
Espaço e método. 1. ed. São Paulo: Nobel, 1985.

(Org.). Novos rumos da Geografia brasileira. São Paulo: Hucitec, 1982.

Por uma Geografia nova. 1. ed. São Paulo: Hucitec, 1978.

Sociedade e espaço: a formação social como teoria e método. Boletim Paulista de

Geografia, São Paulo, n. 54, p. 81-99, 1977.

SILVA, M. A. (Org.). Encontro com o pensamento de Milton Santos: o homem e sua obra. Salvador: Ed. UFBA, 2009.

SOJA, E. Geografias pós-modernas: a reafirmação da teoria social crítica. Rio de Janeiro: Jorge Zahar, 1993. . La réaffirmation de l'espace dans la théorie sociale: la prochaine fin de siècle. In: $\mathrm{BENKO}, \mathrm{G}$. (Org.). Les nouveaux aspects de la théorie sociale: de la géographie à la sociologie. Caen, FR: Paradigme, 1988. p. 1-14.

SOUZA, M. A. (Org.). O mundo do cidadão: um cidadão do mundo. São Paulo: Hucitec, 1996.

SPOSITO, E. A propósito dos paradigmas de orientações teórico-metodológicas na Geografia contemporânea. Terra Livre, São Paulo, n. 16, p. 99-112, 2001. 